\title{
Patron perception and utilization of an embedded librarian program $R E$
}

Lindsay Blake, MLIS, AHIP; Darra Ballance, MLIS, AHIP; Kathy Davies, MLS; Julie K. Gaines, MLIS; Kim Mears, MLIS, AHIP; Peter Shipman, MLIS; Maryska Connolly-Brown, MLIS; Vicki Burchfield, MLIS

See end of article for authors' affiliations.

DOI: http://dx.doi.org/10.3163/1536-5050.104.3.008

Objective: The study measured the perceived value of an academic library's embedded librarian service model.

Setting: The study took place at the health sciences campuses of a research institution.

Methods: A web-based survey was distributed that asked respondents a series of questions about their utilization of and satisfaction with embedded librarians and services.

Results: Over $58 \%$ of respondents reported being aware of their embedded librarians, and 95\% of these were satisfied with provided services.

Conclusions: The overall satisfaction with services was encouraging, but awareness of the embedded program was low, suggesting an overall need for marketing of services.

Keywords: Library Surveys[MeSH], Perception[MeSH], Embedded Librarians, Evaluation, Library Services, Awareness, Satisfaction

Embedded librarianship is a service model that moves librarians physically away from the library building and places them where patrons work. "Embedded" can mean physical space within a school, academic department, or research group, or librarians may be virtually embedded in online courses. Working in close proximity to patrons in specific disciplines allows the librarian to more accurately assess needs and develop customized programs and services beyond traditional library reference services. New roles for embedded librarians may include becoming partners for scholarly research, pursuing grant funding, or being appointed to college governing committees.

Embedded librarians can expand their roles by

learning and incorporating nontraditional skills such

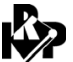

This article has been approved for the Medical Library Association's Independent Reading Program < http://www.mlanet. org/page/independent-reading-program $>$.

A supplemental appendix is available with the online version of this journal. as data management planning, research impact measurement, and scholarly communication.

The implementation of the embedded service model at Augusta University has already been reported [1]. While there are descriptions of many facets of embedded librarian service, there is no comprehensive tool evaluating the activities of embedded librarians that can answer the question: how do patrons perceive the value of embedded librarian services? We sought to measure the awareness and perception of the new service model among clinicians, faculty, and students with a survey instrument.

\section{METHODS}

\section{Survey}

A web-based survey was distributed to health sciences students, residents, faculty, and clinicians using Qualtrics software (Appendix, online only). The study team began survey development by 
collaborating with experts from the university's Educational Innovation Institute (EII). Input from EII consultants helped the study team apply established principles to increase the internal validity of survey results. Specific validity components that were examined included content and internal structure [2]. Institutional review board approval was granted for the study. The survey was distributed by email to a sample of health sciences librarians, both embedded and traditional, for input and critique. Additionally, focus interviews were conducted on campus with students, faculty, and residents to obtain feedback on the questions and survey format.

Changes to the survey were made to reflect the responses received from librarian reviews and campus interview sessions. The final web-based survey was distributed by email in April 2015 to all Augusta University students, full-time faculty, clinicians, and residents in areas where embedded librarians were assigned: four colleges, two hospital departments, and one institute. Responses were solicited for four weeks; weekly reminder emails were sent; and the embedded librarians personally encouraged participation from their embedded areas.

The survey included both Likert-scale and openended questions and began by defining "embedded librarian." Respondents were then asked about their awareness of the embedded librarian program. Thumbnail photographs of each embedded librarian assisted respondents with identifying the librarians with whom they have worked. Respondents who were unfamiliar with the program and unable to identify a librarian were directed to open-ended questions to explore why. The remaining respondents self-identified as a student, resident, clinician, or faculty member and then were routed to questions specific to that role. The question set varied according to role: student questions related to classwork and use of library resources, faculty questions related to teaching and research, and clinician or resident questions related to patient care and clinical training. Because most faculty also fulfill clinical roles, respondents who identified as faculty or clinician had the opportunity to answer both sets of questions.

\section{Analysis}

All statistical analysis was performed by a statistician from the Department of Biostatistics and Epidemiology using SAS 9.4. Descriptive statistics (frequency and percent) were calculated for survey responses regarding awareness, use, and satisfaction with embedded librarians for students, faculty, and clinician or resident respondents.

\section{RESULTS}

The survey was distributed to more than 4,000 students, faculty, and residents and was completed by 381 respondents, resulting in a response rate of $10 \%$. Over $58 \%$ of total respondents reported being aware of their colleges' or departments' embedded librarians. Respondents who did not recognize an embedded librarian by name or photograph or had not worked with an embedded librarian accounted for $45 \%$ of the total responses, while the remaining $55 \%$ of respondents chose 1 or more librarians who had worked with them. Most respondents who had indicated awareness of their colleges' or departments' embedded librarians had contacted an embedded librarian 1-5 times within the last 12 months $(70 \%)$. Contact occurred primarily through email $(77 \%)$ and in person $(64 \%)$. Respondents who were aware of their colleges' or departments' embedded librarians were asked to identify their primary appointment or college (Figure 1).

\section{Student responses}

Nearly $82 \%$ of the 106 students who indicated working with a librarian were also aware that a librarian was embedded in their colleges. Eleven students $(10.6 \%)$ had worked with 2 or more embedded librarians. Embedded librarian services used most frequently by students included assistance with classwork or homework assignments (58.7\%), group or classroom instruction (52.9\%), and literature searching (53.9\%).

A breakdown of results by college revealed unique perspectives on the value of library services. Allied health sciences students strongly agreed that librarian assistance helped them complete assignments and improved their grades and projects. Dental students felt that assistance from librarians improved their literature searching skills and projects and increased their confidence in completing research. Nursing students felt more confident in their literature searches, completion of assignments, and research. They also felt that librarian assistance led to an improvement in their grades. Medical students agreed, but did not strongly agree, that working with a librarian helped them in class and 


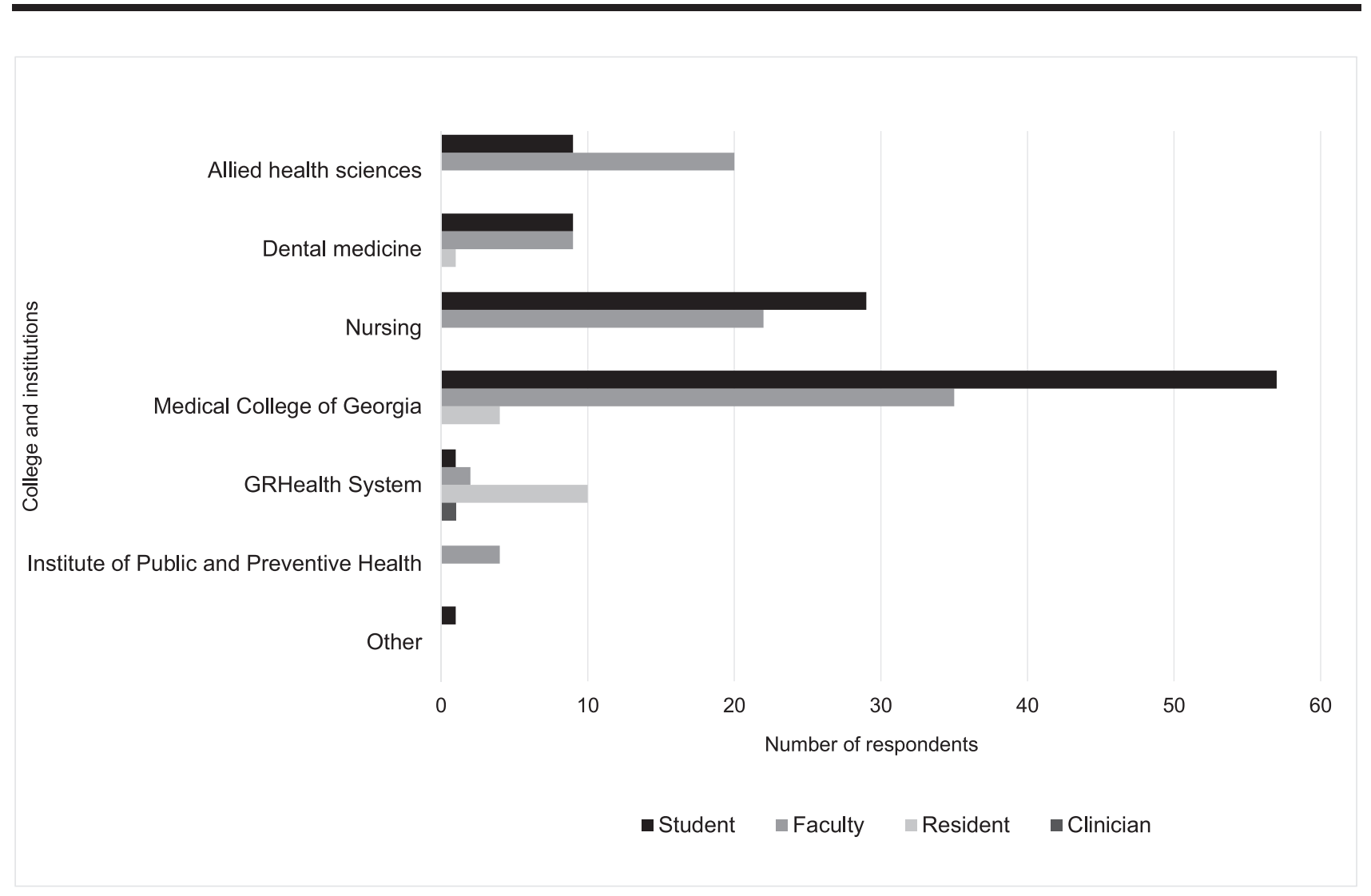

\section{Figure 1}

Survey respondents by college and institution

with completion of assignments, improvement of grades and projects, and confidence in their literature searches and research.

Overall, most students (94\%) agreed or strongly agreed that they were satisfied with the services that the embedded librarians provided, and $84 \%$ agreed or strongly agreed that they would seek out the help of an embedded librarian for future projects or assignments.

\section{Faculty (non-clinician) responses}

Around $93 \%$ of the 43 faculty respondents were aware that embedded librarians worked with them in their colleges. Email was the most popular form of contact $(93.0 \%)$, followed by in person $(58.1 \%)$ and phone $(41.9 \%)$. This was also the only group in the survey to use text messaging.

Literature search services were by far the most popular among faculty, with $83.7 \%$ saying they had worked with an embedded librarian for these services. Additional services that faculty frequently used included online teaching of a course $(41.9 \%)$, publication $(34.9 \%)$, and scholarly support $(27.9 \%)$.

The majority of faculty agreed or strongly agreed $(97.6 \%)$ that embedded librarians saved them time and were an integral part of their groups (95.3\%). Most faculty agreed or strongly agreed (96.9\%) that literature searches conducted by the embedded librarian helped them make better decisions about their work. All faculty agreed that they would contact their embedded librarian again in the future.

\section{Clinician and resident responses}

Sixty-three clinicians, which included residents and faculty with clinical appointments, completed the survey. Respondents indicated using librarian assistance for providing education on rounds (67\%), managing patient care $(55 \%)$, and aiding their choice of tests $(36 \%)$ or treatments $(36 \%)$. Information provided by the librarian most commonly resulted in changes in education during rounds $(44 \%)$, management of patient care $(36.5 \%)$, and choice of test $(24 \%)$. 


\section{DISCUSSION}

Our team's goal for the survey was to measure patron perception and use of embedded librarians at our institution. We accomplished this by assessing patron knowledge of the overall embedded program and individual embedded librarians, patron use of specific embedded services, and the perceived value of embedded services and librarians. Ultimately, this survey asked respondents to expand upon their experiences by providing information such as how users customarily contacted embedded librarians, what services they used, and what impact-positive or negative-they felt that embedded librarians had on their work or research.

The survey suggests that perception-or how our patrons understand our role and value-may be the area needing the most improvement. To gauge perception of the program, the term "embedded librarian" was first clearly defined. It is important to note that all recipients of the survey belonged to a college or department with an embedded librarian. Of 381 responses, nearly 55\% were able to correctly identify an embedded librarian by photograph. This suggested that the embedded librarians were familiar faces in those colleges, but that librarians should work harder to promote themselves and the range of services that they provide through the embedded program.

The majority of contact with embedded librarians was conducted through email and in person, rather than through the learning management system, phone calls, or text messaging. Surprisingly, despite the ease and availability of electronic means of contact, respondents indicated that they initiated contact with a librarian in person nearly $64 \%$ of the time. This would indicate that having a physical presence prompts more frequent use of the librarian and library services. Indeed, Clyde and Lee noted that a physical presence in buildings was associated with increased student and faculty unscheduled consultations, increased requests for class instruction and research support, and increased invitations to departmental events [3]. This supports the value of having a librarian on site to answer questions as they arise.

Individuals who did not identify an embedded librarian in the survey were asked if there was a reason that they had not had the opportunity to work with an embedded librarian. Many stated that they were unaware of the embedded librarians and expressed uncertainty over the extent of provided services. Others stated that they had not had a project that would require the use of embedded librarian services. When asked what would help respondents consult their embedded librarians more often, the participants indicated that increased advertising of embedded services would be advantageous, as well as an increased presence in clinical departments or colleges.

Additional open-ended questions were evaluated for overall themes. When asked in what ways an embedded librarian added value to classes and/or sessions, respondents indicated that the librarian assisted with class projects and taught valuable literature searching skills in both the academic and clinical setting. Of note, one respondent indicated that "all the embedded librarians have made a significant impact in my research, teaching, and service to the [university] community." When asked to identify additional services that embedded librarians should provide, respondents indicated that embedded librarian services at satellite campuses were needed, as well as assistance with literature searching for systematic reviews.

Accurate assessment regarding perceptions of an embedded program is hard to obtain and measure, yet is vitally important to giving a more complete picture of the overall success of a program.

Deficiency in any area can impact the effectiveness of an embedded program. For example, failure to inform users of available services or lack of followthrough when providing those services can both negatively impact perception of the program and the library in general. To this end, many of the questions in our survey were designed to measure how librarians were viewed and the impact that they were perceived to have on research quality, learning objectives, and work outcomes. The overall satisfaction with services was encouraging, with 95\% of respondents who had worked with a librarian agreeing or strongly agreeing that embedded services added value to projects, embedded librarians were an integral part of the group, and the services of embedded librarians would be used in the future.

Circumstances vary from one college to the next, making embedded librarians and the services that they provide quite different even within an institution. Because college and departmental needs vary, the survey could not list all basic and specialized services provided by each embedded librarian. Qualitative research has also not been done in each embedded area. While this type of research would give a more unbiased picture of the value of 
embedded librarians, it would necessarily have to be tailored to all librarians and their embedded areas. Since the goal is a unified embedded evaluation, a more inclusive approach was required.

\section{Limitations}

One major limitation in our study was a response rate of just $10 \%$. The majority of respondents may represent the population who have had a positive experience with the program in the past or have a preexisting relationship due to ongoing research or collaboration. This population would be more likely to have daily contact with embedded librarians and, as such, have received more reminders about the survey and had more motivation to participate. In contrast, other potential respondents would have received only the initial and follow-up emails. The online format was selected for ease of distribution and anonymity but may have presented another limitation as technological aptitude, browser compatibility, and other unforeseen technical challenges could have prevented some potential respondents from participating.

\section{REFERENCES}

1. Blake L, Mears K, Davies K, Ballance D, Shipman P, Connolly-Brown M, Gaines JK. Adapting an embedded model of librarianship, college by college. Med Ref Serv Q. 2014;33(3):264-77. DOI: http://dx.doi.org/10.1080/ 02763869.2014 .925668$.

2. Downing SM. Validity: on meaningful interpretation of assessment data. Med Educ. 2003 Sep;37(9):830-7. 3. Clyde J, Lee J. Embedded reference to embedded librarianship: 6 years at the University of Calgary. J Libr
Administration. 2011;51(4):389-402. DOI: http://dx.doi. org/10.1080/01930826.2011.556963.

\section{AUTHORS' AFFILIATIONS}

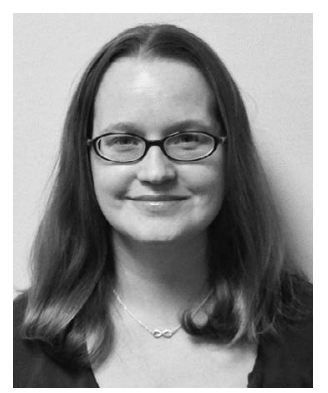

Lindsay Blake, MLIS, AHIP, lblake@augusta.edu, Clinical Librarian; Darra Ballance, MLIS, AHIP, dballance@ augusta.edu, Area Health Education Centers (AHEC) Librarian; Kathy Davies, MLS, kadavies@augusta.edu, Associate Director of Research; Robert B. Greenblatt M.D. Library, Augusta University, 1120 15th Street, Augusta, GA 30912; Julie K. Gaines, MLIS, jkgaines@uga.edu, Head, Augusta University/University of Georgia Partnership Campus Library, Augusta University, Health Science Campus, Russell Hall, Room 222, Athens, GA 30602; Kim Mears, MLIS, AHIP, kmears@augusta.edu, Scholarly Communications Librarian; Peter Shipman, MLIS, pshipman@ augusta.edu, Dental Medicine and Cancer Librarian; Robert B. Greenblatt M.D. Library, Augusta University, 1120 15th Street, Augusta, GA 30912; Maryska Connolly-Brown, MLIS, mconnolly-brown@ hsc.edu, Technical Services Librarian, Walter M. Bortz III Library, Hampden-Sydney College, P.O. Box 7, Hampden-Sydney, VA 23943; Vicki Burchfield, MLIS, vburchfield@augusta.edu, Nursing Information Librarian, Robert B. Greenblatt M.D. Library, Augusta University, 1120 15th Street, Augusta, GA 30912

Received July 2015; accepted February 2016 